\title{
Molecular Subtyping of Salmonella enterica serovar Enteritidis Isolated from Taiwan during 1992-1998 by Amplified Fragment Length Polymorphism and Pulsed-Field Gel Electrophoresis
}

\author{
TSUNG-YU TSAI ${ }^{1}$, WEI-CHEN LUO ${ }^{1}$, KUANG-LO CHEN ${ }^{2}$ AND TZU-MING PAN ${ }^{1 *}$ \\ 1. Institute of Microbiology and Biochemistry, National Taiwan University, 1, Sec. 4, Roosevelt Rd., Taipei City 106, Taiwan, R.O.C. \\ 2. Division of Laboratory Research and Development, Center for Disease Control, Taipei, Taiwan R.O.C.
}

(Received: April 1, 2005; Accepted: September 16, 2005)

\begin{abstract}
Over the past 10 years, Salmonella enterica serovar Enteritidis has emerged as a new serovar and a frequent cause of foodborne diseases in Taiwan. We used two molecular subtyping methods to investigate the development of the infections by $S$. enterica Enteritidis in Taiwan. Twenty-eight strains of S. enterica Enteritidis isolated from Taiwan during the period of 1992 to 1998 were collected. The primer pairs, $M s e \mathrm{I}+\mathrm{C} / E c o \mathrm{RI}+0$ and $M s e \mathrm{I}+\mathrm{G} / P s t \mathrm{I}+\mathrm{C}$, were used in amplified fragment length polymorphism (AFLP) analyses, and the restriction enzyme, AvrII, was used in pulsed-field gel electrophoresis (PFGE). Twenty-two AFLP profiles with 53 59 fragments in each profile were found by using the primer pair, Mse $\mathrm{I}+\mathrm{G} / P s t \mathrm{I}+\mathrm{C}$. In the PFGE analysis, 7 PFGE types were identified. Some of the collected strains, especially the imported strains, had closer relationships with the SE 02 strain isolated from Taipei County. As our results indicate, AFLP analysis was time-saving, easy to perform, and highly discriminative. In this study, AFLP and PFGE were used to analyze the $S$. enterica Enteritidis isolated from patients in Taiwan. These results provide the epidemiological distribution of these isolated strains and additional evidence to illustrate the sources of the food-borne pathogens.
\end{abstract}

Key words: Salmonella enterica serovar Enteritidis, amplified fragment length polymorphism (AFLP), pulsed-field gel electrophoresis (PFGE)

\section{INTRODUCTION}

There are more than 200 diseases which are transmitted through food ${ }^{(1)}$. The causes of food-borne illnesses include bacteria, viruses, parasites, toxins, and metals. In the USA, food-borne diseases cause an estimated of 6 to 81 million illnesses, and 9000 deaths each year ${ }^{(2-6)}$. Between 1986 and 1995,852 outbreaks of food-borne disease which involved 26,173 cases and 20 deaths were reported in Taiwan; of these 852 reported outbreaks, 555 (65\%) were caused by bacterial pathogens ${ }^{(7)}$.

Food poisoning caused by Salmonella is prevalent in many countries. S. enterica serovar Enteritidis is one of the most common serovars responsible for human illness, and is usually spread via contaminated egg or poultry meat. It can infect the ovary and the oviduct of poultry such that eggs can be contaminated and cause infections ${ }^{(8)}$. In Taiwan, outbreaks and sporadic infections caused by this pathogen were rare prior to $1994^{(7,9)}$; however, a dramatic increase in this type of infection was observed after 1995, and $S$. enterica Enteritidis caused 6 cases of infections between 1995 and $1997^{(10)}$.
Pulsed-field gel electrophoresis (PFGE) is one of the best molecular typing methods for analyzing the differences between closely related organisms, and is frequently applied to investigate the epidemiology of outbreaks. On the other hand, amplified fragment length polymorphism (AFLP) is a polymerase chain reactionbased method for rapid screening of genetic diversity ${ }^{(11)}$. The latter is a cheap, easy, fast, and reliable method to generate hundreds of informative genetic markers ${ }^{(12)}$; moreover, it has been used for subtyping the $E$. coli strains including E. coli $\mathrm{O} 157: \mathrm{H} 7^{(13,14,15)}$. We have collected the strains of $S$. enterica Enteritidis isolated from clinical patients reported to the Center for Disease Control (CDC) Taiwan, ROC from 1992 to 1998, and we used both AFLP and PFGE to investigate the relationships of S. enterica Enteritidis. Aside from the combination of the restriction enzymes, MseI and EcoRI, the MseI and Pst I combination was also applied in order to create a more distinctive AFLP analysis condition. For the PFGE analysis, the restriction enzyme $A v r I I$ was used to determine the strains isolated. The results of these 2 molecular subtyping methods were analyzed and compared to illustrate the development of the infections by $S$. enterica Enteritidis in Taiwan.

\footnotetext{
* Author for correspondence. Tel: +886-2-33664519;

Fax: +886-2-23627044; E-mail: tmpan@ntu.edu.tw
} 


\section{MATERIALS AND METHODS}

\section{Bacterial Strains}

Twenty-eight isolates of $S$. enterica Enteritidis strains were used in this study. Twenty-seven of these strains were collected by the CDC, Taiwan and identified by biochemical and serotype tests. One strain was obtained from the Bureau of Food and Drug Analysis, Department of Health, Taiwan, ROC. All strains were isolated from outbreaks of foodborne gastroenteritis clinical stool samples or food samples from 1992 to 1998 in Taiwan. One strain, Salmonella enteritidis BCRC 10744 (purchased from the Bioresource Collection and Research Center, Food Industry Research and Development Institute, Hsinchu, Taiwan) was analyzed in this study as well. All strains were also re-identified by the multiplex PCR with the primers and conditions developed by our laboratory in previous study ${ }^{(16)}$.

\section{AFLP Analysis}

Genomic DNA was extracted using the Wizard ${ }^{\circledR}$ Genomic DNA purification kit (Promega Co., Madison, WI, USA), and the kit was evaluated according to the manufacturer's instructions. AFLP was performed and improved by methods described elsewhere ${ }^{(17-19)}$. In brief, the extracted DNA was subjected to restriction-ligation reactions for $3 \mathrm{hr}$ in a total volume of $10 \mu \mathrm{L}$. This consisted of $10 \mathrm{ng}$ of genomic DNA, $5 \mathrm{U}$ of EcoRI or PstI, $1 \mathrm{U}$ of MseI, $1 \mathrm{U}$ of T4 DNA ligase (Epicentre, Madison, WI, USA), $1 \times$ ligase buffer $(33 \mathrm{mM}$ Tris-acetate $\mathrm{pH}$ 7.8, 66 $\mathrm{mM}$ potassium acetate, $10 \mathrm{mM}$ magnesium acetate and 0.5 mM DTT) and $0.2 \mu \mathrm{g}$ of each adaptor, as shown in Table 1. The restriction-ligation products were diluted 10 to 20 -fold since the polymerase chain reaction (PCR) template for pre-amplified reaction was under the touch-down PCR conditions. It was then heated at $60^{\circ} \mathrm{C}$ for $30 \mathrm{~min}$, and then stored at $4^{\circ} \mathrm{C}$. The PCR products were diluted 10 to 20 -fold as the selective PCR templates, and then the selective PCR was carried out with the primer pairs $M s e \mathrm{I}+\mathrm{C} / E c o \mathrm{RI}+0$,

Table 1. The oligonucleotides used in this study for the amplified fragment length polymorphism

\begin{tabular}{ccl}
\hline Name & Description & \multicolumn{1}{c}{ Sequence } \\
\hline MAD1 & \multirow{2}{*}{ MseI adaptor } & 5'-GACGATGAGTCCTGAG-3' \\
MAD2 & & '-TACTCAGGACTC AT-5' \\
EAD1 & \multirow{2}{*}{ '-CoRI adaptor } & 5'-CTCGTAGACTGCGTACC-3' \\
EAD2 & & 3'-CTGACGCATGG TTAA-5'. \\
PAD1 & PstI adaptor & 5'-CTCGTAGACTGCGTACATGCA-3' \\
PAD2 & 3'-CATCTGACGCATGT-5' \\
MSEP & MseI primer & 5'-GATGAGTCCTGAG TAA-3' \\
ECOP & EcoRI primer & 5'-GACTGCGTACC AATTCN*-3' \\
PSTP & Pst primer & 5'-GACTGCGTACATGCAN*-3' \\
\hline
\end{tabular}

$* \mathrm{~N}$ : selective extension nucleotide including adenine $(\mathrm{A})$, thymine $(\mathrm{T})$, cytosine $(\mathrm{C})$, guanine $(\mathrm{G})$ or non-extension $(0)$ which extended on the end of the primer pairs.
$M s e \mathrm{I}+\mathrm{G} / E c o \mathrm{RI}+\mathrm{G}, M s e \mathrm{I}+\mathrm{G} / P s t \mathrm{I}+\mathrm{G}$, and $M s e \mathrm{I}+\mathrm{G} / P s t \mathrm{I}+\mathrm{C}$ which were screened in 50 different combinations. The selective extension nucleotide included adenine (A), thymine $(\mathrm{T})$, cytosine $(\mathrm{C})$, guanine $(\mathrm{G})$ or non-extension (0) which extended on the end of the primer pairs. The reaction consisted of $200 \mu \mathrm{M}$ dNTP, $0.2 \mu \mathrm{M}$ for Mse I+X selective primer, $0.04 \mu \mathrm{M}$ for $E c o \mathrm{RI}+\mathrm{X}$ or $P s t \mathrm{I}+\mathrm{X}$ selective primer (shown in Table 1), $1 \mathrm{U}$ of Taq polymerase (TaKaRa $\left.\mathrm{Taq}^{\mathrm{TM}}\right)$ and PCR reaction buffer $[100 \mathrm{mM}$ Tris- $\mathrm{HCl}(\mathrm{pH}$ 8.3), $500 \mathrm{mM} \mathrm{KCl}$, and $15 \mathrm{mM} \mathrm{MgCl} 2$ ]. For selective amplified reactions, the PCR condition was 33 cycles at $94^{\circ} \mathrm{C}$ for $1 \mathrm{~min}, 60^{\circ} \mathrm{C}$ for $1 \mathrm{~min}$ and $72^{\circ} \mathrm{C}$ for $2.5 \mathrm{~min}$. The PCR products were removed for capillary electrophoresis by sequence analyzer (3100, Applied Biosystems, Foster City, CA, USA) and Genescan TAMRA-500 (Applied Biosystems) as the internal standard in each sample ${ }^{(13)}$. The profiles of all strains were exported by Genescan ${ }^{\circledR}$ software (Applied Biosystems) and dendrograms for cluster analysis were performed by multivariate analysis of ecological data software, PC-ORD 4.0 (MJM software design, Glenenden Beach, OR, USA) using the Pearson correlation coefficient and the unweighted pair-group method using arithmetic average (UPGMA) algorithm.

\section{PFGE Analysis}

Pulsed-field gel electrophoresis was performed and based on the method developed by Barrett et al. ${ }^{(20)}$. In brief, strains were grown in Trypticase Soy Broth (TSB) at $37^{\circ} \mathrm{C}$ to an optical density of $1.4 \sim 1.5$ at $610 \mathrm{~nm}$. Cells were washed twice and re-suspended in $75 \mathrm{mM} \mathrm{NaCl} / 25$ mM EDTA. Bacterial cell suspension was carefully mixed with an equal volume of melted $1 \%$ chromosomal grade agarose (Bio-Rad Laboratories, Hercules, CA, USA), and the mixture was dispensed into 1.5 -mm-thick block molds (Bio-Rad). After solidification, the plugs were transferred to microcentrifuge tubes containing lysis buffer $(50 \mathrm{mM}$ Tris $\mathrm{pH}$ 8.0, $50 \mathrm{mM}$ EDTA $\mathrm{pH}$ 8.0, 1\% N-laurylsarcrosine, and $1 \mathrm{mg} / \mathrm{mL}$ proteinase $\mathrm{K}$ ), and were then incubated overnight at $53^{\circ} \mathrm{C}$. After then, the plugs were washed twice for $30 \mathrm{~min}$ in $10 \mathrm{nM}$ Tris / $1 \mathrm{mM}$ EDTA (pH 8.0) (TE) containing $1.5 \mathrm{mM}$ phenylmethylsulfonyl fluoride (PMSF), and 4 times in TE buffer without PMSF. Two restriction enzymes, $X b a \mathrm{I}$ and $A v r \mathrm{II}$ (New England Biolabs, Beverly, MA, USA), were evaluated for typing these strains. The enzyme concentration, buffer, and incubation temperature were those recommended by the manufacturer for a 4-hr digestion of agarose-embedded DNA. Restriction fragments were separated by electrophoresis through $1 \%$ PFGE agarose (Bio-Rad Laboratories) in $0.5 \times$ Tris-borateEDTA buffer at $14^{\circ} \mathrm{C}$ in a CHEF DR-II apparutus (Bio-Rad Laboratories) for $22 \mathrm{hr}$ at a constant voltage of $6 \mathrm{~V} / \mathrm{cm}$. The pulse time was ramped from $2 \mathrm{sec}$ in the beginning to $40 \mathrm{sec}$ in the end. After PFGE, the gel was stained with ethidium bromide $(0.2 \mathrm{~g} / \mathrm{mL})$ and photographed under UV transillumination by Kodak Electrophoresis Documentation and Analysis System 290 (Kodak Co., CA, USA). 

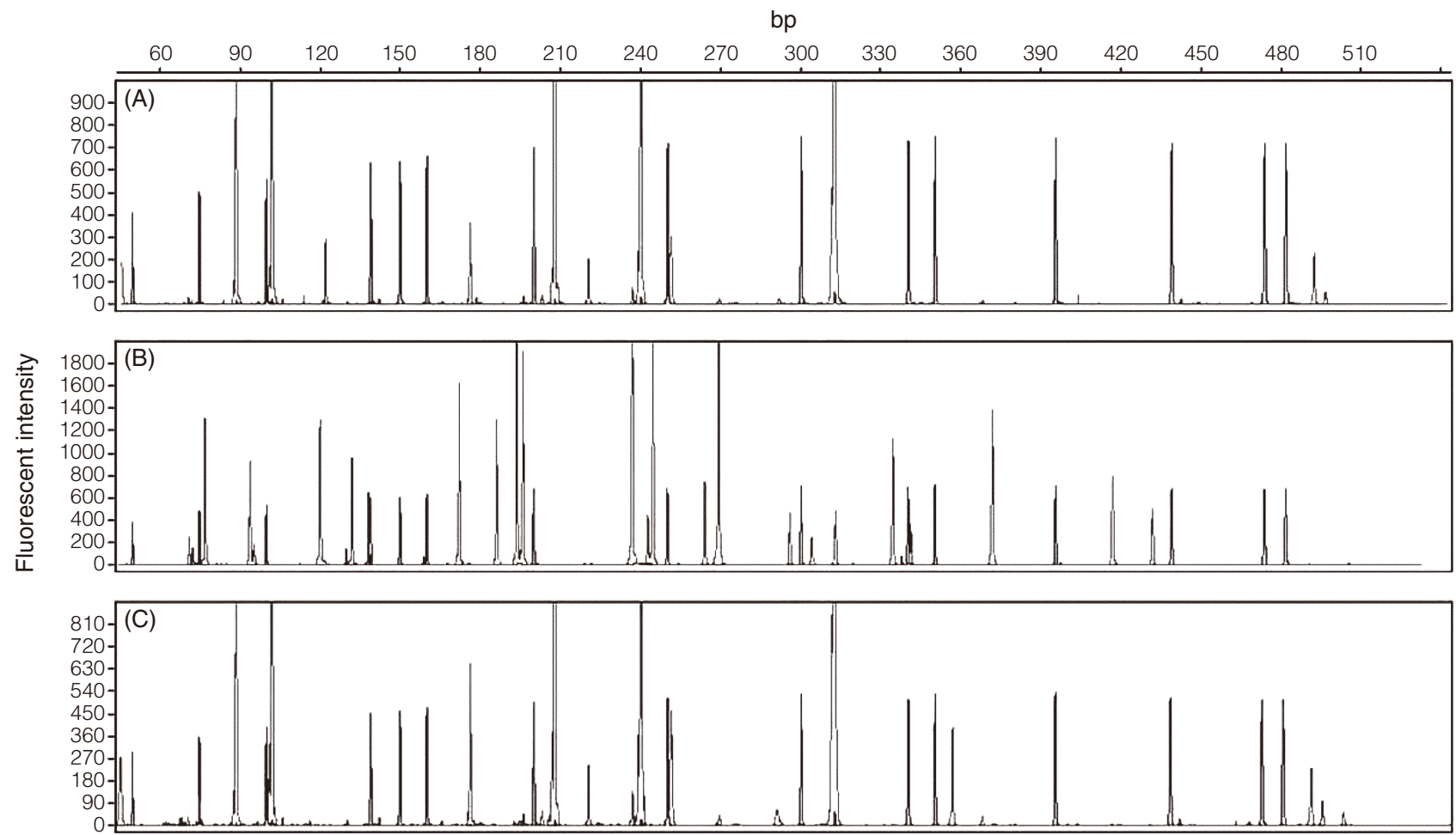

Figure 1. The profiles of the AFLP analysis results generated by Genescan ${ }^{\circledR}$ software by using the MseI/EcoRI condition. (A) SE 01; (B) SE 10; (C) BCRC10744.

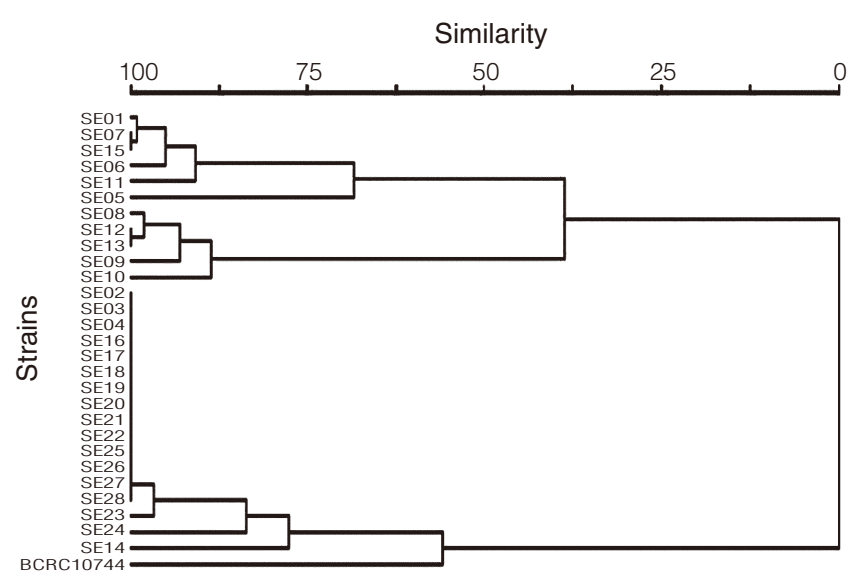

Figure 2. The percentages of genetic similarity between 29 strains of $S$. enterica Enteritidis using the $M s e \mathrm{I} / E c o$ RI condition as determined by multivariate analysis of ecological data software, PC-ORD 4.0.

Dendrograms for cluster analysis were performed by BioProfil ${ }^{\mathbb{R}}$ Image Analysis Software (Vilber Lourmat Co., Marne La Vallee, France) using the Pearson correlation coefficient and the UPGMA algorithm.

\section{RESULTS AND DISCUSSION}

AFLP analysis performed with 2 sets of enzyme combinations (MseI/EcoRI and MseI/PstI) yielded amplified fragments ranging from 60 to $600 \mathrm{bp}$ in size (Shown in

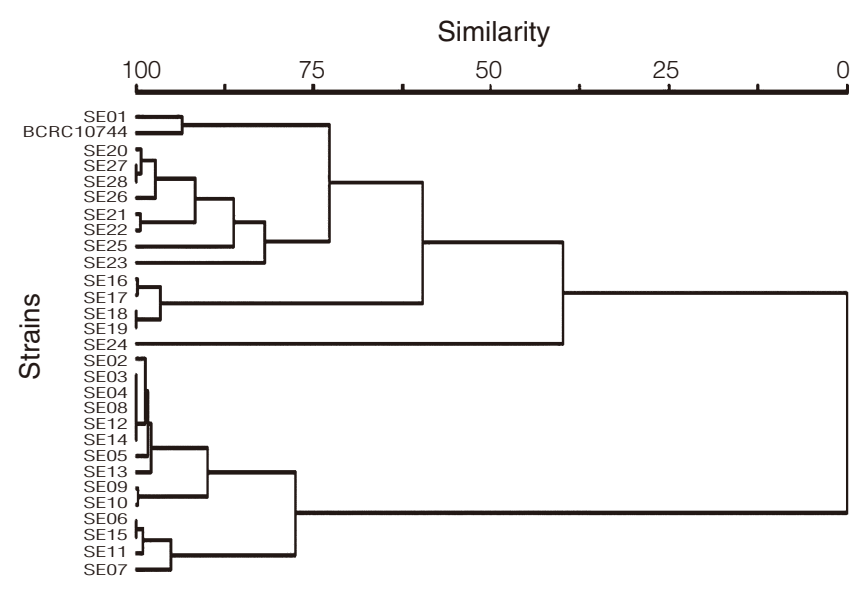

Figure 3. The percentages of genetic similarity between 29 strains of S. enterica Enteritidis using the MseI/Pst $\mathrm{I}$ condition as determined by multivariate analysis of ecological data software, PC-ORD 4.0.

Figure 1). Fifty different combinations needed to be screened, and the selective primer pair combinations, $M s e \mathrm{I}+\mathrm{C} / E c o \mathrm{RI}+0, M s e \mathrm{I}+\mathrm{G} / E c o R I+\mathrm{G}, M s e \mathrm{I}+\mathrm{G} / P s t \mathrm{I}+\mathrm{G}$, and Mse $\mathrm{I}+\mathrm{G} / P s t \mathrm{I}+\mathrm{C}$ were utilized to type these strains. Under the condition of $M s e \mathrm{I} / E c o$ RI (ME) enzyme combination, the primer pair $M s e \mathrm{I}+\mathrm{C} / E c o \mathrm{RI}+0$ yielded 14 AFLP profiles (shown in Table 2) with 19 23 fragments in each profile. The selective bases of the primers were determined using MseI/PstI (MP) enzyme combination, and the primer pair Mse $\mathrm{I}+\mathrm{G} / P s t \mathrm{I}+\mathrm{C}$ was found to be the most effective for the epidemiological typing of the 29 strains of S. enterica 
Table 2. Subtypes of the type strain and 28 Salmonella enterica Enteritidis strains isolated during 1992-1998 by AFLP and PFGE

\begin{tabular}{|c|c|c|c|c|c|}
\hline \multirow{2}{*}{ Strains } & \multicolumn{2}{|c|}{ Source } & \multicolumn{2}{|c|}{ AFLP } & \multirow{2}{*}{$\begin{array}{c}\text { PFGE } \\
A v r I I\end{array}$} \\
\hline & Year & Location & $\mathrm{ME}$ & MP & \\
\hline SE 01 & 1992 & Hualien City & E1 & $\mathrm{P} 1$ & $\mathrm{~A} 2$ \\
\hline SE 02 & 1992 & Taipei County & $\mathrm{E} 2$ & $\mathrm{P} 2$ & A1 \\
\hline SE 03 & 1992 & Philippines imported & E2 & P3 & A1 \\
\hline SE 04 & 1992 & Philippines imported & $\mathrm{E} 2$ & P3 & A1 \\
\hline SE 05 & 1993 & Hualien City & E3 & P4 & A1 \\
\hline SE 06 & 1993 & Hualien City & E4 & P5 & A1 \\
\hline SE 07 & 1994 & Taipei City & E5 & P6 & A1 \\
\hline SE 08 & 1995 & Taipei County & E6 & P3 & A3 \\
\hline SE 09 & 1995 & Taipei County & E7 & $\mathrm{P} 7$ & A1 \\
\hline SE 10 & 1995 & Taipei County & E8 & P8 & A1 \\
\hline SE 11 & 1995 & Taipei County & E9 & P9 & A1 \\
\hline SE 12 & 1995 & Taipei County & E10 & P3 & A1 \\
\hline SE 13 & 1996 & Taipei County & E10 & P10 & A1 \\
\hline SE 14 & 1996 & Taoyuan County & E11 & P3 & A1 \\
\hline SE 15 & 1996 & Taipei City & E5 & P5 & A4 \\
\hline SE 16 & 1996 & Taipei City & $\mathrm{E} 2$ & $\mathrm{P} 11$ & A1 \\
\hline SE 17 & 1996 & Taoyuan County & E2 & $\mathrm{P} 12$ & A1 \\
\hline SE 18 & 1997 & Taoyuan County & $\mathrm{E} 2$ & $\mathrm{P} 13$ & A1 \\
\hline SE 19 & 1997 & Taoyuan County & E2 & P13 & A1 \\
\hline SE 20 & 1997 & Taipei City & E2 & P14 & A1 \\
\hline SE 21 & 1997 & Taipei County & E2 & $\mathrm{P} 15$ & A1 \\
\hline SE 22 & 1997 & Taoyuan County & E2 & P16 & A1 \\
\hline SE 23 & 1998 & Taipei County & E12 & P17 & A5 \\
\hline SE 24 & 1998 & Taipei City & E13 & P18 & A6 \\
\hline SE 25 & 1998 & Taoyuan County & E2 & P19 & A1 \\
\hline SE 26 & 1998 & Taipei County & E2 & $\mathrm{P} 20$ & A1 \\
\hline SE 27 & 1998 & Taipei County & E2 & $\mathrm{P} 21$ & A1 \\
\hline SE 28 & 1998 & $\mathrm{NR}^{*}$ & E2 & $\mathrm{P} 21$ & A1 \\
\hline \multicolumn{3}{|c|}{ S. enterica Enteritidis BCRC 10744} & E14 & $\mathrm{P} 22$ & A7 \\
\hline
\end{tabular}

*No report.

Enteritidis in AFLP analysis. Using this technique, 22 AFLP profiles (shown in Table 2), with 53 59 fragments in each profile, were determined. The percentages of genetic similarity between the 29 strains of $S$. enterica Enteritidis, using ME and MP conditions, are shown in Figures 2 and 3. Using ME, 11 strains had a unique profile (SE 01, 05, 06, $08,09,10,11,14,23,24$, and BCRC10744) and there were 14 strains that shared AFLP profile E2 (Table 2). Strains SE 07 and SE 15, and SE12 and SE 13 shared AFLP profile E5 and E10 respectively. Using the MP results, 18 strains had unique profiles, and five strains (SE 03, 04, 08, 12, and 14) shared the same profile P3. Strains SE 06 and SE 15, SE 18 and SE 19, SE 27 and SE 28 shared AFLP profile P5, P13 and P21, respectively. The PFGE analysis of the 29 strains of $S$. enterica Enteritidis, using AvrII restriction enzyme, generated fragments ranging from $40 \mathrm{~kb}$ to $700 \mathrm{~kb}$ in size. The PFGE patterns are shown in Figure 4. Seven PFGE types were observed (Table 2), and the genetic diversity among these strains is illustrated by the dendrogram in
Figure 5. There were 23 strains that belonged to the PFGE type A1, and 6 strains which had unique types (A2 to A7).

Four strains (SE 09-12) from Taipei County, all from the same year, had different AFLP profiles. We compared the polymorphic fragments of these strains and found that the SE 11 strain was more different from the other strains isolated during the same time period. In the dendrogram, SE 09, SE 10, and SE 12 strains were closely related, and they were not related to the SE 11 strain. From the results of MP, it is evident that the strains SE 09, 10 and 12 have a higher relative relationship within the dendrogram, as shown in Figure 3. Although these 4 isolates had different AFLP profiles when using ME and MP, we hypothesized that the strains SE 09, 10, and 12 were more related based on the results of polymorphic fragments, dendrograms, and geographic location of infected cases. The case caused by strain SE 11 was a unique case of infection in Taipei County in 1995. On the other hand, the other 2 strains, SE 12 and 13, which were isolated from Taipei County 


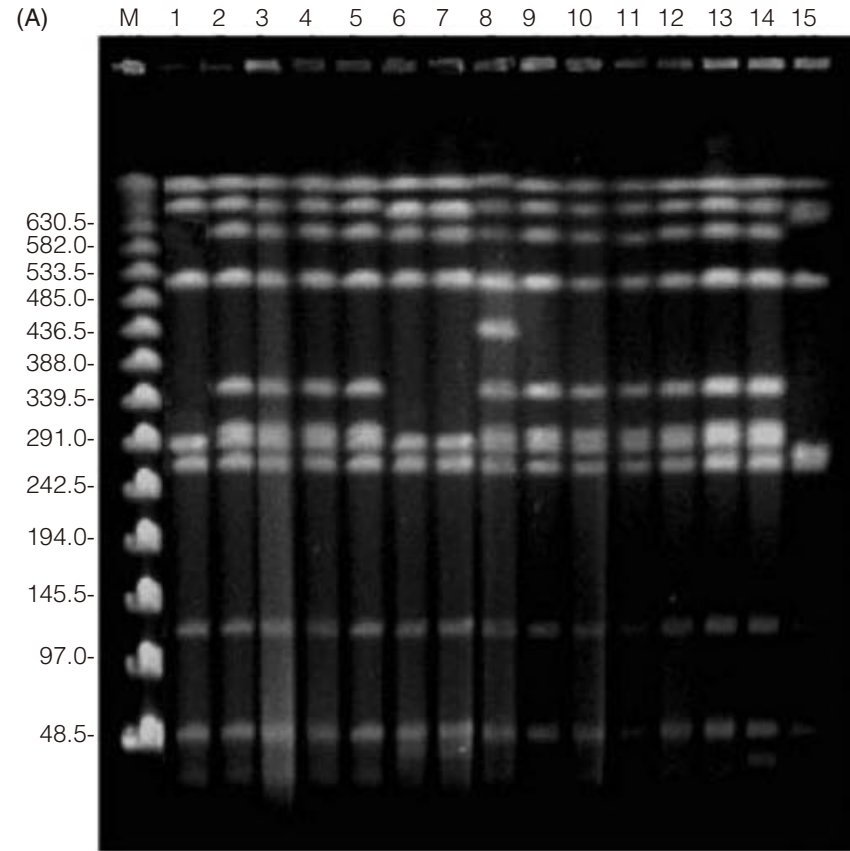

$\begin{array}{llllllllllllllll}\text { (B) } & M & 16 & 17 & 18 & 19 & 20 & 21 & 22 & 23 & 24 & 25 & 26 & 27 & 28 & 29\end{array}$

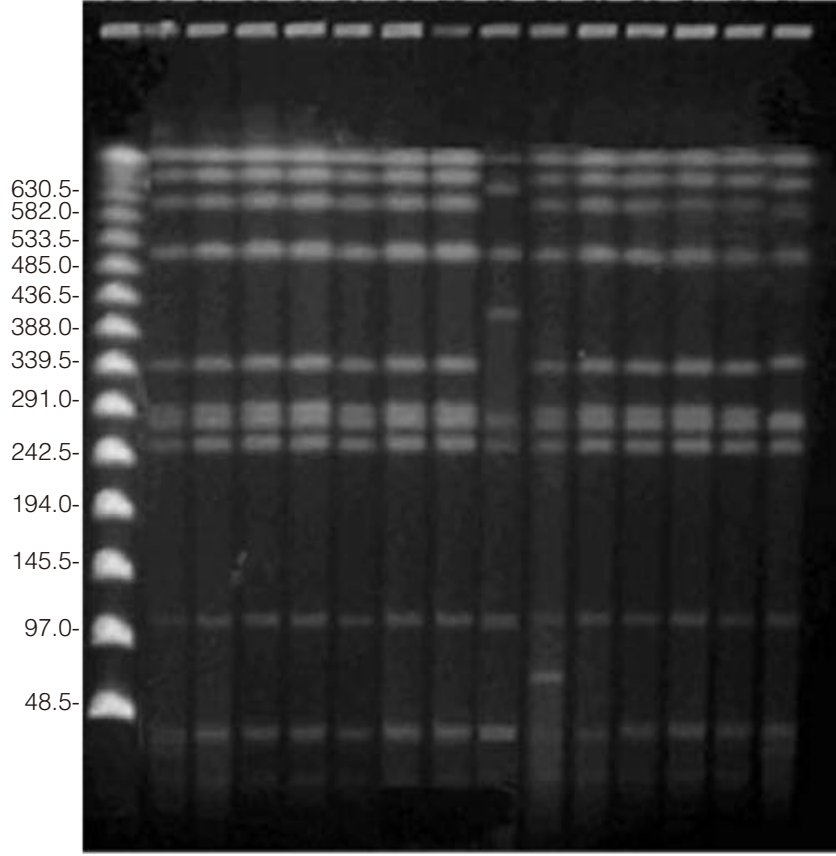

Figure 4. Pulsed-filed gel electrophoresis patterns of AvrII-digested chromosomal DNA of SE 01 15 (A) and 16 28 (B) S. enterica Enteritidis isolates and type strain BCRC 10744. Lane M: lambda ladder marker; Lane 1 28: SE 01 SE 28; Lane 29: BCRC10744

in 1995 and 1996, had the same AFLP profiles under ME analysis. Although these 2 strains did not have the same profiles when using MP, and were of different time periods, the dendrogram of ME and the polymorphic fragments showed that these 2 strains were closely related. Therefore, we assume that these 2 isolates were closely related at that time. In summary, some of the 5 strains isolated from Taipei County at 1995 to 1996 were closely related, and

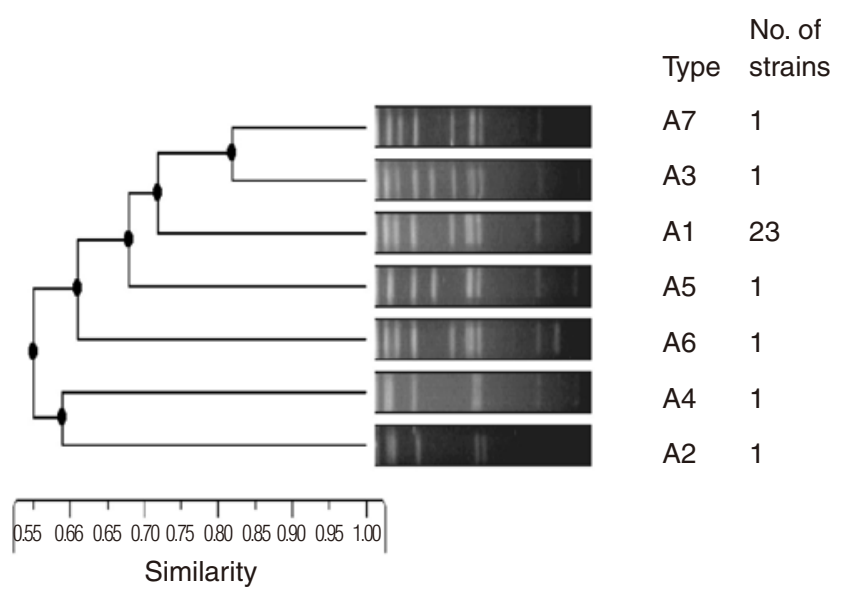

Figure 5. The percentages of genetic similarity between the 7 AvrII digestion pulsed-filed gel electrophoresis patterns.

the infection may have had the same origin, especially the SE 12 and 13 strains from different years. The strains SE 16 19 isolated from Taipei City and Taoyuan County during 1995-1996 had a high degree of similarity in genotype and AFLP profiles when analyzed using ME and MP. Because of the close proximity of Taipei City and Taoyuan County, we can infer that these infected cases were connected with each other in those 2 years. Strain SE 01 had a unique PFGE type, A2, and strains SE 05 and 06, which were also isolated from Hualien, belonged to the A1 type. The results of PFGE were similar to those of AFLP with ME and MP, and indicated that strains SE 01, 05, and 06 were not related to each other. Based on these results, we can infer that these infected cases were not related to each other, even though they were all isolated in eastern Taiwan. Strain SE 27, isolated from Taipei County shared the same profile as strain SE 28 which was isolated from an unknown source of food sample, suggesting it may have originated from the same source as strain SE 27. When using both MP and ME for AFLP analysis, strain SE 02 showed close relatedness to the 2 imported strains from the Philippines (SE 03 and SE 04) isolated in the same year. Consequently, these 3 strains may have originated from the same source of imported infections.

Evidence from epidemiological and molecular studies of microorganisms suggests that strains are frequently transmitted across wide geographic distances ${ }^{(21)}$ due to the convenience of travel around the globe these days and increased human contacts. At the same time, agricultural, human, and food-borne diseases are dispersed easily and quickly and they are becoming increasingly difficult to prevent and control. As the investigation of Kim et al. demonstrated, the Salmonella enterica Serovar Typhimurium DT104 isolates were highly linked to the strains in Korea and United States because of animal and human circulation ${ }^{(22)}$. On the other hand, the strains always have unique molecular profiles in the neighboring areas. In our previous study, the E. coli $\mathrm{O} 157: \mathrm{H} 7$ strains isolated in Taiwan have been investigated and were closely related 
to each other, but significantly different from other foreign strains $^{(23)}$. It is important to establish molecular subtyping methods in order to trace and control the infection of foodborne pathogens. As the results of this study indicate, the infection of $S$. enterica Enteritidis has high geographic relationship which was centralized in Taipei City and Taoyan County, especially strains SE 09 13 which caused 4 outbreaks in 1995 and 1996. Strains SE 16 19 were in a similar situation from 1996 to 1997 in Taipei City and Taoyuan County. The closely related strains were isolated in the immediate areas during continuous years indicating that the dominant and highly related strains were circulating in these areas at northern Taiwan.

Molecular epidemiological typing of microbial isolates through the characterization of proteins or nucleic acids has been successfully applied to epidemiologic investigations of outbreaks of food-borne diseases ${ }^{(24,25)}$. During the past decade, some phenotyping methods were carried out to illustrate the relationship between pathogens, such as the phage type. Plasmid profile analysis and plasmid restriction fragment length polymorphism have been applied in the typing of $E$. coli $\mathrm{O} 157^{(26)}$. Several other molecular typing methods for analyzing the bacterial genomic DNA by using restriction enzymes have been developed in recent years. These methods include RFLP, PFGE, and AFLP, which all focused on analyzing the genomic DNA restrictive maps for epidemiologic investigation of infectious diseases ${ }^{(20,27-33)}$. Unfortunately, there has been no perfect method for the molecular typing of infectious pathogens; consequently the epidemiologists must carry out two or more molecular subtyping methods to identify the type of a strain. For example, strains SE 01, 05, and 06 were isolated from the same area, and the results from PFGE using $X b a \mathrm{I}$ indicated that these 3 strains had the same genotype, but the PFGE using AvrII and AFLP with ME and MP inferred that these 3 strains each had unique profiles. Therefore, it is necessary to combine and compare two or more results of molecular subtyping in epidemiology.

According to Struelens ${ }^{(34)}$, different bacteria strains, different operators and procedural modifications can affect the results of AFLP. Desai et al. found that the different PCR condition was effective for genotyping $S$. enterica Enteritidis $^{(8,35)}$. Lindstedt et al. ${ }^{(36)}$ used the same primer pair, MseI+C/EcoRI +0 , for the AFLP analysis of $S$. enterica Enteritidis and the results showed that AFLP is a versatile molecular subtyping method. A good molecular typing method should be versatile, which means the method should be able to type any kind of bacterial strain. The situation they described could be solved by choosing different restriction enzymes or selective bases in the primer. The choice of restriction enzymes and the number of selective bases are critical in AFLP analysis ${ }^{(37)}$. A highly frequent cutter enzyme will generate results which are too complex, while an extremely rare cutter enzyme will generate too few fragments. The former results are difficult to interpret while the latter ones may reduce the possibility of detecting polymorphism. At the same time, according to Aarts et al. ${ }^{(38)}, 200$ fragments are considered to hamper the interpretation; thus, most studies set the range between 50 to 200 fragments. However, different materials (bacteria, plant or animal cells) and a modification of procedures can still affect the range. In this study, after the restriction and selection it was found that ME has less fragments than MP and that the discriminatory power decreased appreciably.

Although AFLP with MP could differentiate $S$. enterica Enteritidis better than with ME in this study, strain SE 08, which has a unique profile when using PFGE with AvrII and AFLP with ME, could not be differentiated from other strains in AFLP with MP. Such results have also been reported from other studies ${ }^{(39,40)}$. Nair et al. hypothesized that the differences between the ability of PFGE and AFLP to differentiate strains may arise from the fact that the strain had no polymorphisms within the MseI and EcoRI restriction sites in the sequences adjacent to the restriction sites. These sites are complementary to the selective base of the primer, as compared to the polymorphisms within the $A v r I I$ and $X b a$ I sites (detected by PFGE) ${ }^{(40)}$.

Although, at least theoretically, AFLP provides better differentiation of strains compared to PFGE, many researchers have considered the fact that an outbreak genotype should be identified on the basis of a combination of AFLP analysis and epidemiological context ${ }^{(8,34)}$. There already exists a system for standardizing the interpretation of PFGE patterns ${ }^{(41)}$, and a Pulsed-Net internet system was established to collect epidemiological data from all over the world so that inter-laboratory comparisons can be made ${ }^{(42)}$. Also, the pattern interpretation for AFLP analysis needs to be standardized. To establish two or more molecular subtyping methods is becoming increasingly important for effective infection and disease control. In Taiwan, there is not any one department which has the all-inclusive capabilities to analyze food-borne pathogens for molecular subtyping; in addition, there is not any one molecular subtyping method that has been agreed upon as the official method to investigate food-borne or infectious diseases. In Taiwan, this present study is the first to propose regular methods of molecular subtyping for S. enterica Enteritidis infection, and for comparing the two kinds of subtyping methods. At the same time, there is no international organization set up to participate in this network which is so urgently needed right now. Therefore, it remains difficult to trace the source of any food-borne pathogens quickly, especially if that infection comes from a different country. The establishment and joining of a global network database is an important task if we wish to control the agricultural and food-borne pathogens, and reduce the losses resulting from the infection and spread of these pathogens.

\section{CONCLUSIONS}

In summary, we used the AFLP and PFGE methods to investigate the relationships between 28 isolates from Taiwan during 1992-1998. It was found that some of 
these cases had a higher level of relationship, especially the imported strains, SE 03 and 04 which had the same genotype patterns as strain SE 02 isolated from Taipei County. The cases of infection by S. enterica Enteritidis in Taiwan was first determined in 1992, and had increased after 1995. These infections were centralized in northern Taiwan, specifically in Taipei City, Taipei County, and Taoyan County, where all had a large population. Our results showed that AFLP was efficient, easy to use and highly discriminative for a molecular subtyping method. It seemed to provide the most useful epidemiological information about $S$. enterica Enteritidis. To combine and compare two or more molecular subtyping information could provide more evidence to illustrate the sources of the food-borne pathogens.

\section{ACKNOWLEDGEMENTS}

We thank the Center for Diseases Control and the Bureau of Food and Drug Analysis, Department of Health, Taiwan, ROC for kindly providing the strains for this study.

\section{REFERANCES}

1. Byyan, F. L. 1982. Diseases Transmitted by Foods. Centers for Disease Control. Atlanda, U. S. A.

2. Ames, I. A. 1994. Foodborne Pathogens: Risks and Consequences. Council of Agricultural Science and Technology.

3. Archer, D. L. and Kvenberg, J. E. 1985. Incidence and cost of food-borne diarrheal disease in the United States. J. Food Protect. 48: 887-894.

4. Bennett, J., Holmberg, S., Rogers, M. and Solomon, S. 1987. Infectious and parasitic diseases. In "Closing the Gap: the Burden of Unnecessary Illness" pp. 102-214. Amler, R. and Dull, H. eds. Oxford Univ Press. New York, U. S. A.

5. Mead, P. S. and Griffin, P. M. 1998. Escherichia coli O157:H7. Lancet 352: 1207-1212.

6. Todd, E. C. D. 1989. Preliminary estimates of costs of food-borne disease in the United States. J. Food Protect. 52: 595-601.

7. Pan, T. M., Wang, T. K., Lee, C. L., Chien, S. W. and Horng, C. B. 1997. Food-borne disease outbreaks due to bacteria in Taiwan, 1986 to 1995. J. Clin. Microbiol. 5: $1260-1262$.

8. Desai, M., Threlfall, E. J. and Stanley, J. 2001. Fluorescent amplified-fragment length polymorphism subtyping of the Salmonella enterica serovar Entertains phage type 4 clone complex. J. Clin. Microbiol. 39: 201-206.

9. Pan, T. M., Lin, C. S., Wang, T. K., Tsai, J. L., Ho, S. I. and Lee, C. L. 1998. Molecular subtyping of Salmonella enterica serovar paratyphi A from southeast Asia. J. Food Drug Anal. 6: 573-578.
10. Wang, T. K., Tsai, C. L., Lin, C. S. and Pan, T. M. 1999. Recent trend of salmonella food poisoning and serovars. Epidemiology Bull. 15: 1-6.

11. Mueller, U. G. and Wolfenbarger, L. L. 1999. AFLP genotyping and fingerprinting. Trends Ecol. Evol. 14: 389-394.

12. Russell, J. R., Fuller, J. D., Macaulay, M., Hatz, B. G., Jahoor, A., Powell, W. and Waugh, R. 1997. Direct comparison of levels of genetic variation among barley accessions detected by RFLPs, AFLPs, SSRs and RAPDs. Theor. Appl. Genet. 95: 714-722.

13. Arnold, C., Metherell, L., Clewley, J. P. and Stanley, J. 1999. Predictive modeling of fluorescent AFLP: A new approach to the molecular epidemiology of $E$. coli. Res. Microbiol. 150: 33-44.

14. Horvath, R., Dendis, M., Schlegelova, J., Ruzicka, F. and Benedik, J. 2003. A combined AFLP-multiplex PCR assay for molecular typing of Escherichia coli strains using variable bacterial interspersed mosaic elements. Epdemiol. Infect. 132: 61-65.

15. Zhao, S., Mitchell, S. E., Meng, J., Kresovich, S., Doyle, M. P., Dean, R. E., Casa, A. M. and Weller, J. W. 2000. Genomic typing of Escherichia coli O157:H7 by semi-automated fluorescent AFLP analysis. Microbe. Infect. 2: 107-113.

16. Pan, T. M. and Liu, Y. J. 2002. Identification of Salmonella enteritidis isolates by multiplex polymerase chain reaction, J. Microbiol. Immunol. Infect. 35: 147151.

17. Arnold, C. L., Metherell, L. and Willshaw, G. 1999. Predictive fluorescent amplified-fragment length polymorphism analysis of Escherichia coli: High-resolution typing method with phylogenetic significance. J. Clin. Microbiol. 37: 1274-1279.

18. Gibson, J. R., Slater, E., Xerry, J., Tompkins, D. S. and Owen, R. J. 1998. Use of an amplified-fragment length polymorphism technique to fingerprint and differentiate isolates of Helicobacter pylori. J. Clin. Microbiol. 36: 2580-2585.

19. Vos, P., Hogers, R. and Bleeker, M. 1995. AFLP: A new technique for DNA fingerprinting. Nucleic Acids Res. 21: 4407-4414.

20. Barrett, T. J. 1997. Molecular fingerprinting of foodborne pathogenic bacteria: An introduction to methods, uses and problems. In "Food Microbiological Analysis: New Technologies". pp. 249-264. Tortorello, M. L. and Gendel, S. M. eds. Marcel Dekker. New York, U. S. A.

21. Davis, M. A., Hancock, D. D., Besser, T. E., Rice, D. H., Hovde, C. J., Digiacomo, R., Samadpour, M. and Call, D. R. 2003. Correlation between geographic distance and genetic similarity in an international collection of bovine faecal Escherichia coli O157:H7 isolates. Epidemiol. Infect. 131: 923-930.

22. Kim, S., Chun, S. G., Lim, O. Y., Park, M. S., Kang, Y. H., Park, Y. H. and Lee, B. K. 2004. Genomic relationship of Salmonella enterica Serovar Typhimurium DT104 isolates from Korea and the United States. J. 
Microbiol. 42: 14-19.

23. Tsai, T. Y., Luo, W. C., Wu, F. T. and Pan, T. M. 2005. Molecular subtyping for Escherichia coli O157:H7 isolated in Taiwan. Microbiol. Immunol. 49: 579-588.

24. Holmberg, S. D., Wachsmuth, I. K., Hickman-Brenner, F. W. and Cohen, M. L. 1984. Comparison of plasmid profile analysis, phage typing, and antimicrobial susceptibility testing in characterizing Salmonella typhimurium isolates from outbreaks. J. Clin. Microbiol. 19: 100-104.

25. Holmberg, S. D. and Wachsmuth, K. 1989. Plasmid and chromosomal DNA analyses in the epidemiology of bacterial diseases. In "Nucleic Acid and Monoclonal Antibody Probes: Applications in Diagnostic Microbiology". pp. 105-129. Swaminathan, B. and Prakash, G. eds. Marcel Dekker. New York, U. S. A.

26. Swaminathan, B. and Matar, G. M. 1993. Molecular typing methods. In "Diagnostic Molecular Microbiology". pp. 26-50. Persing, D. H., Smith, T. F., Tenover, F. C. and White, T. J. eds. American Society for Microbiology. Washington, DC, U. S. A.

27. Ackers, M. L., Mahon, B. E., Leahy, E., Goode, B., Damrow, T., Hayes, P. S., Bibb, W. F., Rice, D. H., Barrett, T. J., Hutwagner, L., Griffin, P. M. and Slutsker, L. 1998. An outbreak of Escherichia coli O157:H7 infections associated with leaf lettuce consumption. J. Infect. Dis. 177: 1588-1593.

28. Graves, L. M., Swaminathan, B. and Hunter, S. B. 1999. Subtyping Listeria monocytogenes. In "Listeria, Listeriosis and Food Safety”. pp. 279-298. Ryser, E. M, and Marth, E. H. eds. Marcel Dekker. New York, U. S. A.

29. Jimenez, A., Barros-Velazquez, J., Rodriguez, J. and Villa, T. G. 1997. Restriction endonuclease analysis, DNA relatedness and phenotypic characterization of Campylobacter jejuni and Campylobacter coli isolates invovled in food-borne disease. J. Appl. Microbiol. 82: 713-721.

30. Maslanka, S. E., Kerr, J. G., Williams, G., Barbaree, J. M., Carson, L. A., Miller, J. M. and Swaminathan, B. 1999. Molecular subtyping of Clostridium perfringens by pulsed-field gel electrophoresis to facilitate food-borne-disease outbreak investigations. J. Clin. Microbiol. 37: 2209-2214.

31. Threlfall, E. J., Hampton, M. D., Ward, L. R. and Rowe, B. 1996. Application of pulsed-field gel electrophoresis to an international outbreak of Salmonella agona. Emerg. Infect. Dis. 2: 130-132.
32. Threlfall, E. J., Ward, L. R., Hampton, M. D., Ridley, A. M., Rowe, B., Roberts, D., Gilbert, R. J., van Someren, P., Wall, P. G. and Grimont, P. 1998. Molecular fingerprinting defines a strain of Salmonella enterica serotype Anatum responsible for an international outbreak associated with formula-dried milk. Epidemiol. Infect. 121: 289-293.

33. Wachsmuth, K. 1986. Molecular epidemiology of bacteria infections: Examples of methodology and of investigations of outbreaks. Rev. Infect. Dis. 8: 682692.

34. Struelens, M. J. 1998. Molecular epidemiologic typing systems of bacterial pathogens: Current issues and perspectives. Mem. Inst. Oswaldo Cruz. 93: 581-585.

35. Desai, M., Tanna, A. and Efstratiou, A. 1998. Extensive genetic diversity among clinical isolates of Streptococcus pyrogenes serotype M5. Microbiology 144: 629-637.

36. Lindstedt, B. A., Heir, E. and Vardund, T. 2000. Fluorescent amplified-fragment length polymorphism genotyping of Salmonella enterica subsp. Enterica serovar and comparison with pulsed-field gel electrophoresis typing. J. Clin. Microbiol. 38: 1623-1627.

37. Ridiut, C. J. and Donini, P. 1999. Use of AFLP in cereals research. Trends Plant Sci. 4: 76-79.

38. Aarts, H. J. M., van Lith, L. A. J. T. and Keijer, J. 1998. High genotyping of Salmonella strains by AFLP fingerprinting. Letters Appl. Microbiol. 26: 131-135.

39. Møler, K., Jensen, T. K. and Bote, M. 1999. Amplified fragment length polymorphism and pulsed-field gel electrophoresis for subspecies differentation of Serpulina pilosicoli. Anaerobe 5: 313-315.

40. Nair, S., Schreiber, E. and Thong, K. L. 2000. Genotypic characterization of Salmonella typhi by amplified fragment length polymorphism fingerprinting provides increased discrimination as compared to pulsed-field gel electrophoresis and ribotyping. J. Microbiol. Methods 41: 35-43.

41. Tenover, F. C., Arbeit, R. D. and Goering, R. V. 1995. Interpreting chromosomal DNA restriction patterns produced by pulsed-field gel electrophoresis: Criteria for bacteria strain typing. J. Clin. Microbiol. 33: 22332239.

42. Swaminathan, B., Barrett, T. J. and Hunter, S. B. 2001. PulseNet: The molecular subtyping network for foodborne bacterial disease surveillance, United States. Emerg. Infect. Dis. 7: 382-389. 